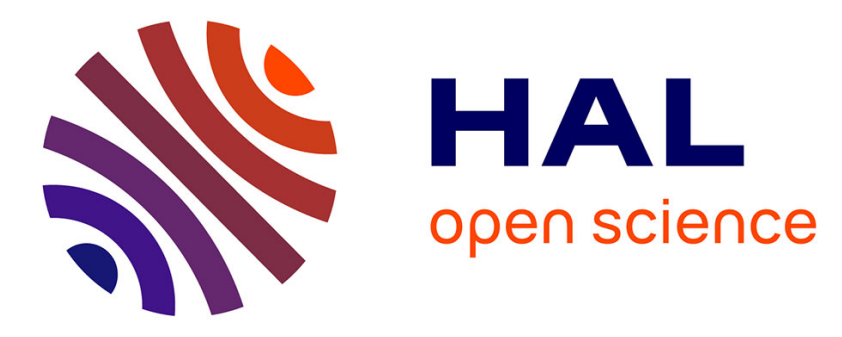

\title{
Protective effect of natural and synthetic anthocyanins against tert-butyl-hydroperoxide-induced oxidative damages in normal and B-thalassemic major human erythrocytes in vitro.
}

Naïma Charif, Nassima Mokhtari-Soulimane, Sabri Cherrak, Mourad Elhabiri, Hafida Merzouk

\section{To cite this version:}

Naïma Charif, Nassima Mokhtari-Soulimane, Sabri Cherrak, Mourad Elhabiri, Hafida Merzouk. Protective effect of natural and synthetic anthocyanins against tert-butyl-hydroperoxide-induced oxidative damages in normal and B-thalassemic major human erythrocytes in vitro.. Current Nutrition and Food Science, 2020, 17 (1), pp.38-47. 10.2174/1573401316999200421093827 . hal-03017264

\author{
HAL Id: hal-03017264 \\ https://hal.science/hal-03017264
}

Submitted on 12 Oct 2021

HAL is a multi-disciplinary open access archive for the deposit and dissemination of scientific research documents, whether they are published or not. The documents may come from teaching and research institutions in France or abroad, or from public or private research centers.
L'archive ouverte pluridisciplinaire HAL, est destinée au dépôt et à la diffusion de documents scientifiques de niveau recherche, publiés ou non, émanant des établissements d'enseignement et de recherche français ou étrangers, des laboratoires publics ou privés. 


\title{
Protective effect of natural and synthetic anthocyanins against tert- butyl-hydroperoxide-induced oxidative damages in normal and B- thalassemic major human erythrocytes in vitro
}

\author{
Naïma Charif ${ }^{1}$, Nassima Mokhtari-Soulimane ${ }^{1, *}$, Sabri Cherrak $^{1}$, Hafida Merzouk ${ }^{1}$, Mourad Elhabiri ${ }^{2}$ \\ ${ }^{1}$ Laboratory of Physiology, Physiopathology and Biochemistry of Nutrition, Department of Biology, Faculty of Natural \\ and Life Sciences, Earth and Universe, University ABOU-BEKR BELKAÏD,Tlemcen 13000, Algeria. \\ ${ }^{2}$ UMR7042 Université de Strasbourg-CNRS-UHA, Laboratoire d'Innovation Moléculaire et Applications (LIMA) Team \\ Bio(IN)organic and Medicinal Chemistry, European School of Chemistry, Polymers and Materials (ECPM), 25 Rue \\ Becquerel, Strasbourg 67087, France
}

\begin{abstract}
Background: Even though $\beta$ thalassemia major is a genetic blood disorder, the damages endured by erythrocytes are mediated in part by oxidative stress. Antioxidants such as anthocyanins are capable to prevent the pro-oxidant effects induced by reactive oxygen species (ROS).

Objective: This study aims to evaluate the in Vitro preventive effects of one natural and two synthetic anthocyanins on normal and $\beta$ thalassemic erythrocytes on which toxicity has been induced by free radical generator: tert-butylhydroperoxide TBHP.

Methods: Erythrocytes isolated from fasting blood samples of healthy and $\beta$-thalassemic major individuals were treated either with TBHP alone or with TBHP after being pre-incubated with anthocyanins. Cell viability, reduced glutathione (GSH) and malondialdehyde (MDA) contents were measured after 90 minutes of incubation. In parallel, antiradical scavenging capacities of the investigated anthocyanins were also estimated by using the 2,2-DiPhenyl-1-PicrylHydrazyl $\left(\mathrm{DPPH}^{\bullet}\right)$ assay.
\end{abstract}

Results: The results clearly demonstrate that the treatment of erythrocytes with TBHP induces hemolysis along with marked redox state alteration (lipid peroxidation concomitant to GSH depletion) in both normal and $\beta$ thalassemic erythrocytes. During the pre-treatment with anthocyanins, erythrocytes become more resistant to oxidative impairments. Cyanin chloride and 6,7,3',4'-tetrahydroxyflavylium chloride effectively prevent from TBHP-induced: hemolysis, lipid peroxidation and GSH depletion in normal and thalassemic erythrocytes, while 3'4'-dihdroxy-7-methoxy-flavylium chloride had a lesser effect on MDA levels with thalassemic erythrocytes. These results go with those derived from the $\mathrm{DPPH}^{\bullet}$ assay.

Conclusion: Our study contributes with important insights that tested anthocyanins may exert relevant potential in alleviation of oxidative stress, especially the one affecting $\beta$ thalassemic erythrocytes

Keywords: anthocyanins, erythrocytes, $\beta$ thalassemia major, TBHP, oxidative/antioxidative status, GSH, MDA.

\footnotetext{
*Address correspondence to Nassima Mokhtari-Soulimane, Department of Biology, Faculty of Natural and Life Sciences, Earth and Universe, University ABOU-BEKR .BP 119 Rocade 2. E-mail address: nassima_amel@yahoo.fr
}

\section{INTRODUCTION}

Red blood cells (RBCs) are one of the targets of reactive oxygen species (ROS) generated by an oxidative stress environment due to the presence of a significant amounts of highly polyunsaturated fatty acids in their membranes, their rich oxygen supplies and high hemoglobin $(\mathrm{Hb})$ concentrations which are a powerful catalyst promotors of 
erythrocytes oxidative stress [1-3]. Maintaining the integrity and architecture of normal RBCs should be considered as an important therapeutic prospect in some pathological conditions associated with haematological disorders [4].

The inherited disorders of $\mathrm{Hb}$ production are the most common human monogenic disorders. Those affecting the adult $\beta$ globin genes (HBB) such as $\beta$-thalassemia are the most clinically relevant $[5,6]$. Despite the primary lesion is in the $\beta$-globin gene, the damage to the RBC being mediated in part by oxidative stress [7-9]. Auto-oxidation and precipitation of $\mathrm{Hb}$ released during $\mathrm{RBC}$ hemolysis are closely related to the depletion of the $\mathrm{RBC}$ antioxidant defences. In addition, subsequent therapeutic transfusion which is the standard treatment for those patients often promotes systemic free iron overloading [8,9] resulting in the inability of human body to increase the iron excretion [10] that further potentiates the generation of ROS [11] through the Fenton reaction [2].

ROS can oxidize lipids[12], nucleic acids[13], cellular proteins [14]and alter the activity of transcription factors, membrane channels and signalling pathways[15-17]. Given these facts, extensive oxidizing damages on RBCs promote their premature death by hemolysis[18].

Recent reports highlight many valuable protective effects of naturally occurring antioxidants in biological systems[1921]. It has been indeed observed that natural antioxidants such as anthocyanins [22, 23], tea polyphenols [24], rutin [25] and other natural/synthetic flavonoids [26] can significantly improve the redox balance and counteract the deleterious oxidative processes in erythrocyte, thus contributing to extend their longevity [27].

Indeed anthocyanins, can act to support the cellular antioxidant defence mechanisms beyond the direct radical scavenging activity. The enhancement of $\operatorname{SOD}$ (Superoxide dismutase),CAT(Catalase), GPx(Glutathione peroxidase)and GR(glutathione reductase) activities, and increasement of GSH(reduced glutathione) production, can contribute to improve cellular redox state and potentially prevent oxidative stress [28]. Several studies strongly illustrate the importance of those antioxidant enzymes in maintaining normal cellular physiology and fighting against diseases[2931].

Anthocyanins form an interesting class of flavonoids that are constituted by (glycosylated) polyhydroxy derivatives of 2phenylbenzopyrylium salts (referred to as flavylium). These anthocyanins constitute the pigments responsible for most of the wide variety of colours from yellow to blue displayed by flowers, fruits and leaves of a broad range of plants, where they are naturally produced [32].
Anthocyanins have been proposed to provide protective functions such as plants protection against abiotic stress, photoprotection from UV-B irradiations and ROS scavenging capacities. Protection against herbivores and attraction of pollinators are also other functions dedicated to anthocyanins in terms of their relation with biotic. Importantly, anthocyanins are of major interest due to their key implications in human health care [33-36]. The main property of anthocyanins is indeed their antioxidant activity which was found to play a critical role in the prevention from a myriad of human diseases and infections. They can be of valuable use in a wide range of pharmacological applications against various stress conditions and chronic diseases such as inflammation, neuronal and cardiovascular complications, cognitive decline, capillary fragility and permeability, liver damage, lipid peroxidation, tumour proliferation, diabetes, and many others [22].

Flavonoids, including anthocyanins, can hence prevent injuries caused by free radicals following several mechanisms such as: (i) quenching of free radicals through donation of a hydrogen atom or by electron transfer [37]; (ii) chelation of pro-oxidant redox metals such as $\mathrm{Fe}$ or $\mathrm{Cu}$, and formation of stable metal complexes to prevent them being accessible for oxidation/catalysis [38]; (iii) suppressing the enzymes associated with free radical generation such as xanthine oxidase [39], protein kinase C[40], cyclooxygenase, lipoxygenase, microsomal succinoxidase or NADH oxidase [41, 42], and (iv) stimulation of endogenous antioxidant enzymes by inducing phase II detoxifying enzymes (e.g., $\mathrm{NAD}(\mathrm{P}) \mathrm{H}$-quinone oxidoreductase, glutathione $\mathrm{S}$ transferase, and UDP-glucuronosyl transferase) which are the utmost defence enzymes against intracellular xenobiotic and oxidative stress toxicants [37].

Oxidizers such as tert-Butyl hydroperoxide (TBHP) are known to cause metabolic alterations on RBCs[43-45]. Reported data have in fact demonstrated that, once TBHP has exceeded the capacity of glutathione peroxidase to enzymatically detoxify it, TBHP reacts with cellular $\mathrm{Hb}$, inducing $\mathrm{Hb}$ degradation along with lipid peroxidation which ultimately lead to RBC hemolysis [45, 46].

Based on these considerations, we have chosen to evaluate the capacity of a series of anthocyanins composed of one natural (Cyanin chloride), a naturally occurring anthocyanin that is widespread in fruits and vegetables such as black elderberry, pomegranate or snap bean. This natural pigment is based on a 3',4'-catecholate unit that was shown to complex metal ions such as $\mathrm{Al}^{3+}$ and $\mathrm{Ga}^{3+}$ [47-51]; and two synthetic flavyliums 6,7,3',4'-tetrahydroxyflavylium chloride and 3'4' -7-methoxy-flavylium chloride, bearing one and two catecholate units, respectively, to prevent TBHP toxicity in vitro (Figure 1). In vivo, these pigments can be linked to metal ions (metal complexes), interact with other 
flavonoids or polysaccharide macromolecular carriers so that the corresponding anthocyanins are stabilized. The synthetic derivatives were shown to be less prone to hydration and therefore more stable in aqueous solutions [48].

The aim of this work is to evaluate the effects of these natural and synthetic anthocyanins on isolated erythrocytes of normal and $\beta$-thalassemic major subjects that were challenged in vitro with TBHP, that promotes a sequel of oxidative events mimicking the pathophysiological pathway leading to cell hemolysis. To achieve this, cell viability, reduced glutathione (GSH) and malondialdehyde (MDA) levels were measured. Antiradical scavenging capacities were also estimated by using the 2,2-DiPhenyl-1PicrylHydrazyl (DPPH') assay.

\section{Materials and Methods}

\subsection{Material}

Cyanin chloride was purchased from EXTRASYNTHESE. 3'4'-dihdroxy-7-methoxy-flavylium chloride was synthesized according to a reported procedure [48]. 6,7,3',4'tetrahydroxy-flavylium chloride was obtained by condensation under acidic conditions of 3,4dihydroxyacetophenone and 2,4,5-trihydroxybenzaldehyde. $224 \mathrm{mg}$ of 3,4-dihydroxyacetophenone and $219 \mathrm{mg}$ of 2,4,5trihydroxybenzaldehyde were solubilized in $20 \mathrm{~mL}$ of formic acid containing $10 \%$ of concentrated chlorhydric acid. The mixture was stirred at room temperature for 24 hours and then evaporated to dryness under vacuum. The residue was washed several times with ether and then solubilized in $2 \mathrm{~mL}$ of methanol acidified with 5\% of concentrated chlorhydric acid. 6,7,3',4'-tetrahydroxy-flavylium chloride was obtained as red crystals by slow diffusion of ether (35\% yield). $1 \mathrm{H}$ NMR $\delta \mathrm{H}$ [400 MHz, (CD3)2SO-CF3CO2D]: 8.98 (d, J 8.8, H-4), 8.28 (d, J 8.8, H-5'), 7.89 (dd, J 8.6 and J 2.2, H-6'), 7.78 (d, J 2.2, H-8), 7.46 (d, J 10.3, H-5 and H-2'), 7.03 (d, J 8.6, H-3). 13C NMR $\delta \mathrm{H}[100 \mathrm{MHz},(\mathrm{CD} 3) 2 \mathrm{SO}-\mathrm{CF} 3 \mathrm{CO} 2 \mathrm{D}]$ : $168.25,161.12,154.31,154.20,150.00,149.67,147.14$, $123.58,120.89,120.11,117.23,115.23,112.42,110.59$, 103.02
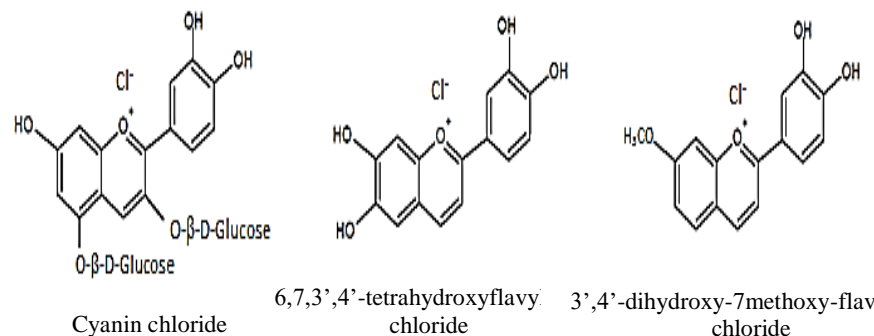

Cyanin chloride

6,7,3',4'-tetrahydroxyflavy! 3',4'-dihydroxy-7methoxy-flavylium chloride

Fig. 1 Chemical structures of Cyanin chloride and two flavylium chlorides investigated in this work

2.2. Blood Samples
The participation to this study was voluntary and all subjects gave their informed consent. The study was approved by the Ethical Committee of University of Tlemcen and was performed according to the Declaration of Helsinki.

Fasting blood samples obtained from $\beta$-thalassemic major ( $\mathrm{Hb}: 3-7 \mathrm{~g} / \mathrm{dl}$; HbA1: 0\%; HbA2 :3.5 - $7 \%$; HbF 90 - 95\%; Mcv :50-60fl; $\mathrm{MCH}: 12-18 \mathrm{pg}$ ), and healthy individuals were collected from the arm veins in heparin. Erythrocytes were isolated by consecutive centrifugations and washings in phosphate-buffered saline $\mathrm{PBS},(0.9 \% \mathrm{NaCl}, \mathrm{pH} 7.4)$ to remove plasma, platelets and buffy coat, then re-suspended in PBS at 2\% haematocrit. At the beginning, cells were challenged with TBHP at concentrations ranging from 50 to $1000 \mu \mathrm{M}$ to find out the most suitable conditions. A concentration of $200 \mu \mathrm{M}$ was selected as being the one leading to a well detectable hemolysis and redox state impairment under our experimental conditions. RBCs were then incubated under air atmosphere at $37^{\circ} \mathrm{C}$ for 30 minutes in a shaking incubator in the absence (control) or in the presence of anthocyanin which concentration was fixed at $100 \mu \mathrm{M}$. An TBHP aqueous solution of $200 \mu \mathrm{M}$ final concentration was then added. The reaction mixture was shaken mildly while being incubated at $37^{\circ} \mathrm{C}$ for 90 minutes.

\subsection{Flow Cytometry Assay of Cell Viability Using Calcein-} AM.

To assess the cell viability, the membrane-permeable dye, Calcein-AM, was used following a reported method with some slight modifications [52]. After 90 minutes of incubation, erythrocytes were centrifuged, washed twice with the incubation buffer and re-suspended at the final concentration of $0.1 \%$. Calcein-AM was then added at a final concentration of $2 \mu \mathrm{M}$ and the cells were incubated at $37^{\circ} \mathrm{C}$ in the dark for additional 45 minutes. The fluorescence was read at excitation/emission wavelengths of $485 \mathrm{~nm} / 528 \mathrm{~nm}$. The results are expressed as a percentage of cell viability relative to that of control cells (cells untreated with anthocyanin or TBHP).

\subsection{Determination of intracellular redox parameters}

\subsubsection{MDA determination}

Lipid peroxidation as represented by MDA was measured following the method of Draper and Hadley [53], by a hot acid treatment using thiobarbituric acid (TBA). After incubation, cooling and centrifugation, the absorption of the supernatant containing the MDA was measured at $532 \mathrm{~nm}$.

\subsubsection{GSH Assay}

Reduced GSH contents were determined in hemolysate according to the method of Ellman [54], in which the reduction of the Ellman's reagent (5,5'-dithiobis-(2nitrobenzoic acid) or DTNB) by a thiol group produces 2- 
nitro-5-mercaptobenzoic acid, an intensely yellow compound which absorbance was measured at $412 \mathrm{~nm}$.

\subsection{3. $\mathrm{DPPH}^{\bullet}$ radical scavenging activity}

$\mathrm{DPPH}^{\cdot}$ radical scavenging capacity of the set of compounds was measured according to the method described by BrandWilliams [55] with some slight modifications. Microvolumes of methanolic stock solutions of the anthocyanins or the standard (ascorbic acid) were added to $2 \mathrm{~mL}$ of a methanolic $\mathrm{DPPH}^{*}$ solution at $150 \mu \mathrm{M}$. The absorbance at $515 \mathrm{~nm}$ was measured every 30 seconds until a steady state was reached. A methanolic solution containing the anthocyanins served as a blank along this assay. The $\mathrm{EC}_{50}$ values that were calculated are defined as the amount of the sample necessary to decrease the initial $\mathrm{DPPH}^{\circ}$ concentration by $50 \%$. A high $\mathrm{DPPH}^{\circ}$ radical scavenging activity is associated with a low $\mathrm{EC}_{50}$ value. The $\mathrm{EC}_{50}$ values were calculated according to the following formula:

$$
\left.\mathrm{EC}_{50}=\left[\left(\mathrm{A}_{\mathrm{DPPH}} \cdot-\mathrm{A}_{\text {Sample }}\right) / \mathrm{A}_{\mathrm{DPPH}} \cdot\right)\right] \times 100
$$

where $A_{\mathrm{DPPH}}$. is the absorbance value of the methanolic $\mathrm{DPPH}^{*}$ solution in the absence of the radical scavenger, and A sample is the absorbance value of the methanolic $\mathrm{DPPH}^{\circ}$ solution in the presence of the scavenger. The $\mathrm{A}$ sample was evaluated as the difference between the absorbance value of the test solution and the absorbance value of the corresponding blank solution. The $\mathrm{EC}_{50}$ values are reported in Table 1.

\subsection{Statistical Analysis}

All the experiments were carried out at least in triplicate. Data were expressed as means \pm SD. Statistical analysis was carried out using STATISTICA, version 4.1 (Statsoft, Paris, France).

Multiple comparisons were performed using ANOVA (analysis of variance) followed by Tukey post hoc test. Differences of $\mathrm{P}<0.05$ were considered significant. a, b, c and a',b',c' indicated significant differences obtained with different incubations for healthy and thalassemic subjects respectively.

\section{Results}

Our result demonstrates that, thalassemic RBCs have lower levels of GSH and higher levels of MDA comparing to normal RBCs.

As anticipated, treatment of RBCs with TBHP $(200 \mu \mathrm{M})$ entails drastic cytotoxic effects on both normal and $\beta$ thalassemic erythrocytes as evidenced in Figure 2. $\beta$ thalassemic major erythrocytes were found to be more sensitive to the pro-oxidative action of TBHP leading to more than $46 \%$ of RBC hemolysis.
In preventive related experiments, pre-treatment of the RBCs with both natural or synthetic anthocyanins significantly counteracted the decline in cell viability caused by TBHP in both the normal and $\beta$-thalassemic major RBCs. No statistical difference was observed between the cell viabilities of the RBCs pre-treated with anthocyanin and exposed to TBHP compared to their respective controls (non-treated RBCs).

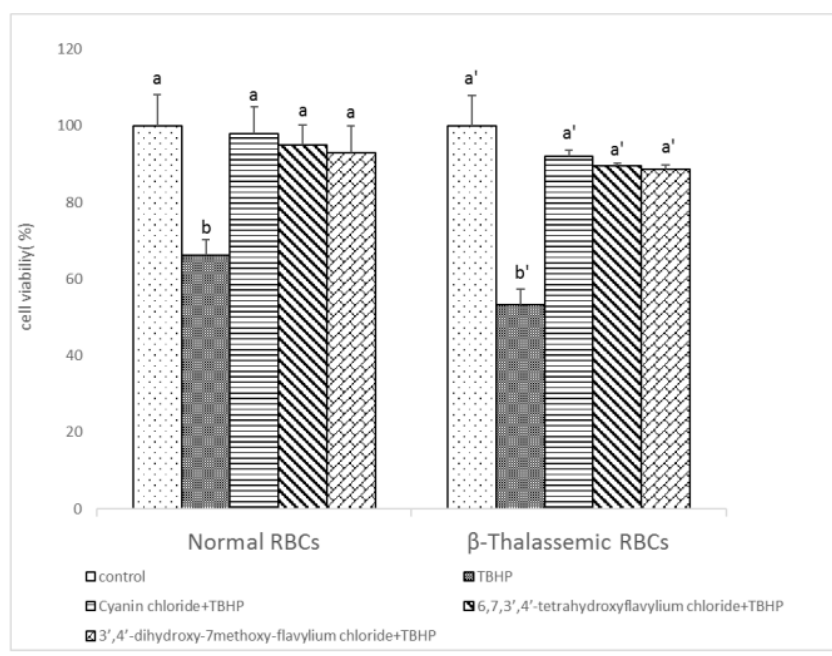

Fig.2 Percentage of viable RBCs from B-thalassemic major and healthy subjects

The results are exhibited as a percentage of cell viability relative to that of control cells (cells untreated with anthocyanin or TBHP). The values are means \pm SD of triplicate assays. Multiple comparisons were performed using ANOVA followed by Tukey post hoc test. Differences of $\mathrm{P}<0.05$ were considered significant. a, b, c and a', b', c' indicate significant differences obtained with different incubations for healthy and thalassemic subjects, respectively.

On the other hand, MDA, the marker of lipid peroxidation, significantly increased in erythrocytes from $\beta$-thalassemic major and healthy subjects after TBHP treatment (Figure 3), in accordance with the RBCs hemolysis data. Treatment with either Cyanin chloride or 6,7,3',4'-tetrahydroxyflavylium chloride significantly lowered the levels of MDA in normal, and $\beta$-thalassemic RBCs subjected to oxidative stress induced by TBHP. 3'4'-dihdroxy-7-methoxy-flavylium chloride stood in very interesting contrast in normal RBCs while it was found to be less effective than Cyanin chloride and $6,7,3^{\prime}, 4^{\prime}$-tetrahydroxyflavylium chloride in $\beta$ thalassemic RBCs. A significant difference can be also observed between $\beta$-thalassemic and normal RBCs in accordance with the above described data related to RBC hemolysis. 


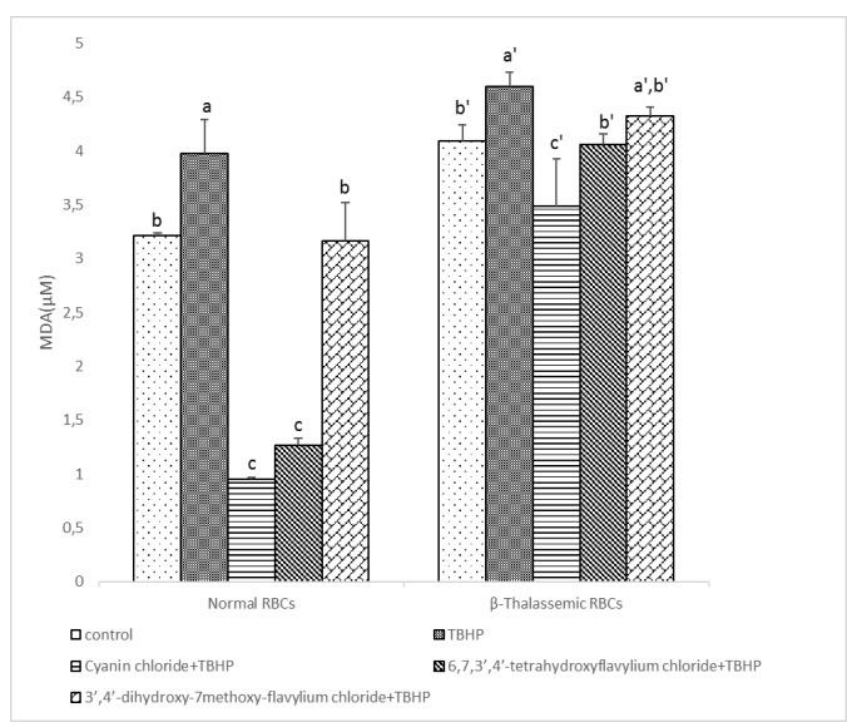

Fig.3 Intracellular MDA contents of RBCs from Bthalassemic major and healthy subjects

The values are means \pm SD of triplicate assays. Multiple comparisons were performed using ANOVA followed by Tukey post hoc test. Differences of $\mathrm{P}<0.05$ were considered significant. a, b, c and a', b', c' indicate significant differences obtained with different incubations for healthy and thalassemic subjects, respectively.

Furthermore, GSH levels measured in suspensions of normal and $\beta$-thalassemic erythrocytes were rapidly reduced after oxidation (treatment with TBHP) (Figure 4). The decrease of GSH contents induced by oxidative stress (TBHP) was markedly mitigated by all the tested anthocyanins in normal and $\beta$-thalassemic major $\mathrm{RBCs}$ and their corresponding levels were found to be comparable within experimental errors to their respective controls.

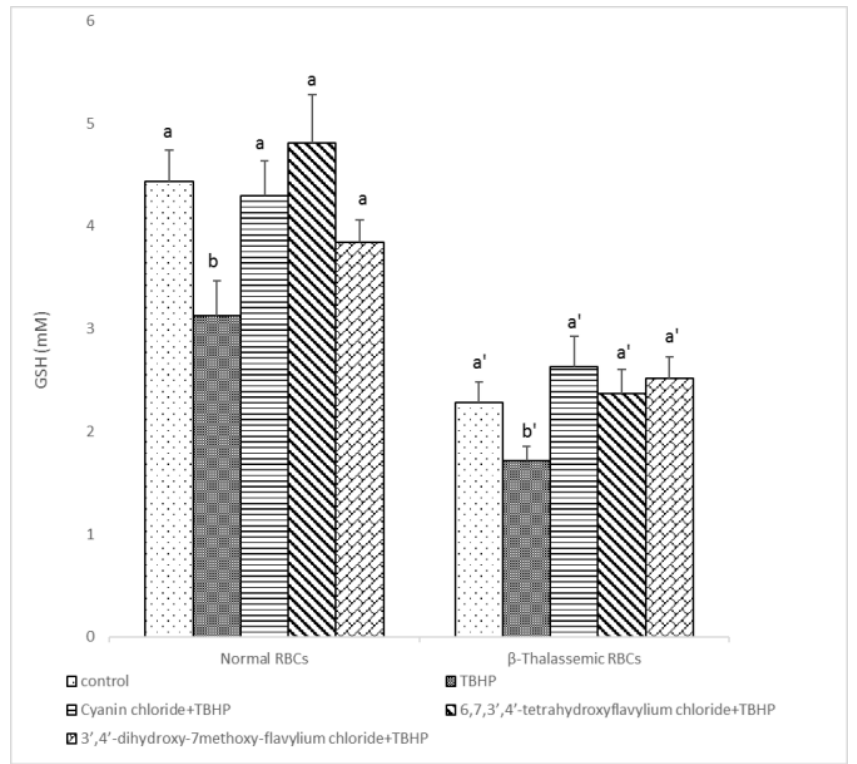

Fig.4 Intracellular GSH contents of RBCs from Bthalassemic major and healthy subjects
The values are means \pm SD of triplicate assays. Multiple comparisons were performed using ANOVA followed by Tukey post hoc test. Differences of $\mathrm{P}<0.05$ were considered significant. a, b, c and a',b',c' indicate significant differences obtained with different incubations for healthy and thalassemic subjects respectively.

$\mathrm{DPPH}^{*}$ is a coloured and stable free radical molecule that can accept either an electron or a hydrogen radical to form a colourless diamagnetic molecule [56]. Using absorption spectrophotometry allowed easily monitoring the antioxidant capacities of a molecule (i.e., the ability of the anthocyanins to scavenge free radical species). The investigation of the antiradical properties of three polyphenolic pigments with DPPH $^{\circ}$ assay resulted to the evaluation of the EC50 values that are exposed in Table 1. The comparison with ascorbic acid used as a standard demonstrated the valuable antioxidant capacities of the three anthocyanins. Their scavenging effects expressed as EC50.

Table1. DPPH scavenging activity: Effective concentration $(\mathrm{EC} 50 \pm \mathrm{SD})$ of the investigated anthocyanins and standard (ascorbic acid)

\begin{tabular}{ll}
\hline Compound & EC $50 \pm$ SD $(\boldsymbol{\mu M})$ \\
\hline Cyanin chloride & $2.10 \pm 0.11$ \\
$\begin{array}{l}\text { 6,7,3',4'-tetrahydroxyflavylium } \\
\text { chloride }\end{array}$ & $2.34 \pm 0.15$ \\
$\begin{array}{l}\text { 3'4'-dihdroxy-7-methoxy } \\
\text { flavylium chloride }\end{array}$ & $3.07 \pm 0.14$ \\
Ascorbic acid & $4.51 \pm 0.27$ \\
\hline
\end{tabular}

\section{Discussion}

The sequence of events following the precipitation of $\mathrm{Hb}-\alpha$ chains and the repeated therapeutic transfusions which lead to systemic iron overload, markedly affect the redox status of the $\beta$-thalassemic RBCs $[8,57]$.

In our study, we have investigated the beneficial effects of a natural anthocyanin and two novel synthetic flavyliums against the free radical generator TBHP that engendered severe injuries in normal and $\beta$-thalassemic major RBCs as analysed by cell viability and redox status.

It is well established that thalassemic patients undergo chronic oxidative stress and prooxidant pools including malondialdehyde (MDA) [58] , protein carbonyl, and 8hydroxyguanine [58-62], as a result of accumulation of products from oxidised biomolecules associated with a depletion of the main cell antioxidants above all (GSH)[63, 64], which makes thalassemic RBCs more vulnerable to oxidative stress $[7,27,65,66]$

Under our experimental conditions, the treatment of thalassemic RBCs with TBHP triggers a cascade of oxidative 
reactions that mimic and accelerate the pathophysiologic events leading those RBCs to hemolysis.

We therefore demonstrated that $\beta$-thalassemic RBCs were subjected to mark hemolysis comparing to the normal RBCs upon exposure to TBHP. Indeed, treatment with the organic hydroperoxidant TBHP induces significant hemolysis, increases MDA levels and causes significant depletion in GSH in both normal and $\beta$-thalassemic major RBCs. These data are in accordance with previous reported studies [44, 46, 67-71] showing that exposure of RBCs to TBHP leads to significant decrease of GSH levels and production of ROS, notably $\mathrm{OH}^{\bullet}$ radicals, thus inducing lipid peroxidation and metHb formation. The latter appears to play a critical role in the mechanism of RBC sensitization and lysis induced by TBHP. The decrease of GSH levels occurs when TBHP is metabolized by GSH peroxidases [72]. Chen et al proposed that when the defence system leading to the reduction of GSSG (i.e. product of GSH oxidation by TBHP) to GSH is overwhelmed, TBHP is then able to produce free radicals and start the oxidative chain reaction in RBCs [73].On the other hand, the direct interaction of t-butyl alkoxy radicals (i.e., formed from TBHP in the presence of transition metals such as iron in $\beta$-thalassemic RBCs) with membrane unsaturated fatty acids initiate lipid peroxidation and consequently destroy cell membranes.

Remarkably, the $\beta$-thalassemic RBCs were more vulnerable than normal RBCs to the TBHP, due to the weakened antioxidant defence and the higher amounts of hemin in their membrane[27] .Moreover, in the presence of oxidizing agents such as THBP used in this study, iron might be released from hemoglobin $(\mathrm{Hb})$ to form methaemoglobin (metHb) under glutathione deficiency concomitant with lipid peroxidation [74] and extensive hemolysis [75]

Due to their well-known antioxidant activity [76-78], flavonoids, in particular anthocyanins have generated considerable interest and attention for their potential therapeutic properties against a wide variety of diseases.

Either in normal or in thalassemic RBCs, all tested anthocyanins were able to protect efficiently against TBHPinduced hemolysis, thus maintaining the cell viabilities at values that were similar to those observed in their respective control RBCs (i.e., absence of TBHP). This can be mostly explained by one of the main anthocyanins features, i.e., their ability to act as efficient radical scavengers [79] as shown by their valuable antiradical properties towards DDPH $^{\bullet}$ radical. Complexation of pro-oxidant metal ions such as iron can also partly explained this property[36], this is consistent with several studies showing protective effect of anthocyanin against RBC hemolysis meditated by free radical initiator $[23,80,81]$.
These properties are also reflected by the oxidant and antioxidant biomarkers that were measured in this study. Pre-incubation of RBCs with anthocyanins significantly reduces MDA levels that were found to be comparable (or even lower) than the controls. It has been reported that flavonoids inhibit lipid peroxidation by acting as strong $\mathrm{O}_{2}{ }^{-}$ scavengers and $\mathrm{O}_{2}$ quenchers and also react with peroxyl radicals which are responsible for radical chain reactions during lipid peroxidation[82]. Flavonoids such as anthocyanins indeed, act as $\mathrm{H}$-atom donors to the peroxyl radicals, thus inhibiting the oxidation of fatty acids by chain radical termination [82, 83]. Our results are in accordance with many studies showing that polyphenols enhance red blood cell resistance to oxidative stress induced lipid peroxidation both in normal and thalassemic RBCs [24, 59, $84,85]$. It was revealed that anthocyanins particularly were able to inhibit lipid peroxidation in several in vitro lipid containing models such as liposomal membrane, liver microsomal system and human LDL exposed to oxidative injury; this protection was explained by the ability of anthocyanins to scavenge free radicals and simultaneously prevent other antioxidants from oxidation [86]. Interestingly, Cyanin chloride and 6,7,3',4'-tetrahydroxyflavylium chloride were found to be more potent than 3'4'-dihdroxy-7methoxy-flavylium chloride on reducing MDA levels particularly in $\beta$-thalassemic RBCs. This is probably due to their more powerful radical scavenging properties provided by their hydroxyl functions (Fig. 1). Furthermore, Ollila, et al suggested that flavonoids with more hydroxyl groups exhibited longer retention delays and stronger interactions with dipalmitoyl phosphatidylcholine (DPPC) membrane interface [87]. The peculiar behaviour of 3'4'-dihdroxy-7methoxy-flavylium chloride toward MDA levels in $\beta$ thalassemic RBCs can also be explained by concentration or time-dependent reaction, since ROS levels are higher in $\beta$ thalassemic than in normal RBCs [7, 88], these increased ROS levels need either elevated concentrations of 3'4'dihdroxy-7-methoxy-flavylium chloride or more time to be neutralized. Sulaiman, and Hussain have indeed reported that anthocyanins can effectively display concentration and time dependent cytoprotective properties against compoundsinduced peroxidative haemolytic damages [81].

On the other hand, pre-incubation of RBCs with anthocyanins including 3'4'-dihdroxy-7-methoxy-flavylium chloride fully restored the GSH levels at initial values both in normal and in $\beta$-thalassemic major RBCs, as a response to the alleviation of the oxidative stress, which reflects the beneficial effects of these anthocyanins on intracellular antioxidant status. These findings are consistent with previous studies that also demonstrate that the antioxidant activities of flavonoids could reinstate the GSH levels that were markedly decreased by the action of TBHP in erythrocytes [84] and other cell types [89, 90]. We could 
suggest that 3'4'-dihdroxy-7-methoxy-flavylium chloride acts as an antioxidant through modulation of GSH levels rather than a radical scavenger, since its capacity to raise GSH levels was found to be more relevant than its capacity to reduce MDA.It was demonstrated that, apart from their direct free radical scavenging capacities, anthocyanins may also exert their antioxidant effects through modulation of molecular mechanisms in cells. For example, cyanidin-3-O$\beta$-glucoside (C3G) was showed to activate GSH synthesis through a novel antioxidant defence mechanism against excessive ROS production [91].

\section{Conclusion}

In conclusion, the results that were attained within this research clearly demonstrate that the tested anthocyanins (natural and synthetic) displayed preventive effects against TBHP-induced hemolysis and lipid peroxidation in normal and $\beta$-thalassemic major human RBCs. However, protection by Cyanin chloride and 6,7,3',4'-tetrahydroxyflavylium chloride was found to be greater against TBHP-induced MDA accumulation, than that of 3'4'-dihdroxy-7-methoxyflavylium chloride in $\beta$-thalassemic RBCs. Indeed, 3'4'dihdroxy-7-methoxy-flavylium chloride protect against TBHP-induced redox status impairment by acting as a GSH modulator while Cyanin chloride and 6,7,3',4'tetrahydroxyflavylium chloride provided protection via their radical scavenging capacities.

Based on these data obtained in vitro, the positive impacts of these anthocyanins in preventing oxidative stress damage should have prompt consideration. Therefore, additional biological testing will be necessary to ascertain beneficial inhibitory effect of tested anthocyanins against oxidative damage in in vitro and in vivo systems, to consider their use as potential therapeutic molecules in the supportive therapy of $\beta$-thalassemia major.

\section{LIST OF ABBREVIATIONS}

$\mathrm{Al}$ : aluminium

ANOVA :(analysis of variance)

C3G: cyanidin-3-O- $\beta$-glucoside

CAT: Catalase

$\mathrm{Cu}:$ copper

DPPC: dipalmitoyl phosphatidylcholine

DPPH: 2,2-DiPhenyl-1-PicrylHydrazyl

Fe: iron

Ga: gallium

GPx: Glutathione peroxidase

GR: glutathione reductase

GSSG: Glutathione disulfide

GSH: reduced glutathione
Hb: hemoglobin

HBB: adult $\beta$ globin genes

MDA: malondialdehyde

Met $\mathrm{Hb}$ : methaemoglobin

$\mathrm{NAD}(\mathrm{P})+$ : nicotinamide adénine dinucléotide phosphate

$\mathrm{NAD}(\mathrm{P}) \mathrm{H}$ : reduced form of nicotinamide adenine dinucleotide phosphate

O2: oxygen

O2- : superoxide radical

$\mathrm{OH}^{\bullet}$ : hydroxyl radical

RBCs: Red blood cells

ROS: reactive oxygen species

SOD : Superoxide dismutase

TBHP: tert-butyl-hydroperoxide

\section{ETHICS APPROVAL AND CONSENT TO PARTICIPATE}

The participation to this study was voluntary and all subjects gave their informed consent. The study was approved by the Ethical Committee of University of Tlemcen and was performed according to the Declaration of Helsinki

\section{Availability of Data and Materials}

The authors confirm that the data supporting the findings of this study are available within the article. further information can be requested from corresponding author

\section{Conflicts of interest}

There are no conflicts of interest to declare.

\section{Acknowledgements}

This work was supported by the French-Algerian Cooperation Program PHC Tassili International Research Extension Grant TASSILI 13MDU 892 and the French Foreign Office (Campus France). This work was partly supported by the CNRS (LIMA, UMR 7042), the University of Strasbourg and the University Abou-Bekr Belkaïd of TLEMCEN. This collaborative work has been also possible by the NutRedOx Network (COST Action CA16112) that is supported by the European Cooperation in Science and Technology (COST).

\section{References}

[1] Clemens MR, Ruess M, Bursa Z, Waller HD. The relationship between lipid composition of red blood cells and their susceptibility to lipid peroxidation. Free radical research communications. 1987;3:265-71.

[2] Sadrzadeh S, Graf E, Panter SS, Hallaway P, Eaton J. Hemoglobin. A biologic fenton reagent. Journal of Biological Chemistry. 1984;259:14354-6. 
[3] Çimen MB. Free radical metabolism in human erythrocytes. Clinica chimica acta. 2008;390:1-11.

[4] Toptas B, Baykal A, Yesilipek A, Isbir M, Kupesiz A, Yalcin $\mathrm{O}$, et al. L-carnitine deficiency and red blood cell mechanical impairment in $\beta$-thalassemia major. Clinical hemorheology and microcirculation. 2006;35:349-57.

[5] Weatherall D, Williams T, Allen S, O'Donnell A. The population genetics and dynamics of the thalassemias. Hematology/Oncology Clinics. 2010;24:1021-31.

[6] Cao A, Galanello R. Beta-thalassemia. Genetics in medicine. 2010;12:61.

[7] Pavlova L, Savov V, Petkov H, Charova I. Oxidative stress in patients with beta-thalassemia major. Prilozi. 2007;28:145-54.

[8] Livrea M, Tesoriere L, Pintaudi A, Calabrese A, Maggio A, Freisleben $\mathrm{H}$, et al. Oxidative stress and antioxidant status in beta-thalassemia major: iron overload and depletion of lipid-soluble antioxidants. Blood. 1996;88:3608-14.

[9] Oikonomidou PR, Rivella S. What can we learn from ineffective erythropoiesis in thalassemia? Blood reviews. 2017.

[10] Kaplan J, Ward DM, De Domenico I. The molecular basis of iron overload disorders and iron-linked anemias. International journal of hematology. 2011;93:14-20.

[11] Chan AC, Chow CK, Chiu D. Interaction of antioxidants and their implication in genetic anemia. Proceedings of the Society for Experimental Biology and Medicine. 1999;222:274-82.

[12] Farmer EE, Mueller MJ. ROS-mediated lipid peroxidation and RES-activated signaling. Annual review of plant biology. 2013;64:429-50.

[13] Hemnani T, Parihar M. Reactive oxygen species and oxidative DNA damage. Indian journal of physiology and pharmacology. 1998;42:440-52.

[14] Du J, Gebicki JM. Proteins are major initial cell targets of hydroxyl free radicals. The international journal of biochemistry \& cell biology. 2004;36:2334-43.

[15] Ribeil J-A, Arlet J-B, Dussiot M, Cruz Moura I, Courtois $G$, Hermine $O$. Ineffective erythropoiesis in $\beta$ thalassemia. The Scientific World Journal. 2013;2013.

[16] Bergamini CM, Gambetti S, Dondi A, Cervellati C. Oxygen, reactive oxygen species and tissue damage. Current pharmaceutical design. 2004;10:1611-26.

[17] Bandyopadhyay U, Das D, Banerjee RK. Reactive oxygen species: oxidative damage and pathogenesis. Current Science-Bangalore-. 1999;77:658-66.

[18] Miki M, Tamai H, Mino M, Yamamoto Y, Niki E. Freeradical chain oxidation of rat red blood cells by molecular oxygen and its inhibition by $\alpha$-tocopherol. Archives of Biochemistry and Biophysics. 1987;258:373-80.

[19] Kaur C, Kapoor HC. Antioxidants in fruits and vegetables-the millennium's health. International journal of food science \& technology. 2001;36:703-25.

[20] Masella R, Di Benedetto R, Varì R, Filesi C, Giovannini C. Novel mechanisms of natural antioxidant compounds in biological systems: involvement of glutathione and glutathione-related enzymes. The Journal of nutritional biochemistry. 2005;16:577-86.

[21] Banjarnahor SD, Artanti N. Antioxidant properties of flavonoids. Medical Journal of Indonesia. 2014;23:239.
[22] Kong J-M, Chia L-S, Goh N-K, Chia T-F, Brouillard R. Analysis and biological activities of anthocyanins. Phytochemistry. 2003;64:923-33.

[23] Sangkitikomol W, Tencomnao T, Rocejanasaroj A. Antioxidant effects of anthocyanins-rich extract from black sticky rice on human erythrocytes and mononuclear leukocytes. African journal of biotechnology. 2010;9:82229.

[24] Grinberg LN, Newmark H, Kitrossky N, Rahamim E, Chevion M, Rachmilewitz EA. Protective effects of tea polyphenols against oxidative damage to red blood cells. Biochemical Pharmacology. 1997;54:973-8.

[25] Grinberg LN, Rachmilewitz EA, Newmark H. Protective effects of rutin against hemoglobin oxidation. Biochemical pharmacology. 1994;48:643-9.

[26] Cherrak SA, Mokhtari-Soulimane N, Berroukeche F, Bensenane B, Cherbonnel A, Merzouk $\mathrm{H}$, et al. In Vitro Antioxidant versus Metal Ion Chelating Properties of Flavonoids: A Structure-Activity Investigation. PLoS One. 2016;11:e0165575.

[27] Tesoriere L, Allegra M, Butera D, Gentile C, Livrea M. Cytoprotective effects of the antioxidant phytochemical indicaxanthin in $\beta$-thalassemia red blood cells. Free radical research. 2006;40:753-61.

[28] Zhang H, Liu R, Tsao R. Anthocyanin-rich phenolic extracts of purple root vegetables inhibit pro-inflammatory cytokines induced by $\mathrm{H} 2 \mathrm{O} 2$ and enhance antioxidant enzyme activities in Caco-2 cells. Journal of Functional Foods. 2016;22:363-75.

[29] Schreibelt G, Van Horssen J, Van Rossum S, Dijkstra CD, Drukarch B, de Vries HE. Therapeutic potential and biological role of endogenous antioxidant enzymes in multiple sclerosis pathology. Brain research reviews. 2007;56:322-30.

[30] Matés JM, Pérez-Gómez C, De Castro IN. Antioxidant enzymes and human diseases. Clinical biochemistry. 1999;32:595-603.

[31] Sun Y. Free radicals, antioxidant enzymes, and carcinogenesis. Free Radical Biology and Medicine. 1990;8:583-99.

[32] Brouillard R. Chemical structure of anthocyanins: Academic Press: New York; 1982.

[33] Biswas T, Mathur A. Plant Anthocyanins: Biosynthesis, Bioactivity and in vitro Production from tissue cultures. 2017.

[34] Hou D-X. Potential mechanisms of cancer chemoprevention by anthocyanins. Current molecular medicine. 2003;3:149-59.

[35] Hou D-X, Kai K, Li J-J, Lin S, Terahara N, Wakamatsu $\mathrm{M}$, et al. Anthocyanidins inhibit activator protein 1 activity and cell transformation: structure-activity relationship and molecular mechanisms. Carcinogenesis. 2004;25:29-36.

[36] Castañeda-Ovando A, de Lourdes Pacheco-Hernández M, Páez-Hernández ME, Rodríguez JA, Galán-Vidal CA. Chemical studies of anthocyanins: A review. Food chemistry. 2009;113:859-71.

[37] Procházková D, Boušová I, Wilhelmová N. Antioxidant and prooxidant properties of flavonoids. Fitoterapia. 2011;82:513-23. 
[38] Leopoldini M, Russo N, Toscano M. The molecular basis of working mechanism of natural polyphenolic antioxidants. Food Chemistry. 2011;125:288-306.

[39] Hanasaki Y, Ogawa S, Fukui S. The correlation between active oxygens scavenging and antioxidative effects of flavonoids. Free Radical Biology and Medicine. 1994; 16:845-50.

[40] Ursini F, Maiorino M, Morazzoni P, Roveri A, Pifferi G. A novel antioxidant flavonoid (IdB 1031) affecting molecular mechanisms of cellular activation. Free Radical Biology and Medicine. 1994;16:547-53.

[41] Brown JE, Khodr H, Hider RC, Rice-Evans CA. Structural dependence of flavonoid interactions with $\mathrm{Cu} 2+$ ions: implications for their antioxidant properties. Biochemical journal. 1998;330:1173.

[42] Korkina LG, Afanas' Ev IB. Antioxidant and chelating properties of flavonoids. Advances in pharmacology: Elsevier; 1996. p. 151-63.

[43] Dremza I, Lapshina E, Kujawa J, Zavodnik I. Oxygenrelated processes in red blood cells exposed to tert-butyl hydroperoxide. Redox Report. 2006;11:185-92.

[44] Roy A, Sil PC. Tertiary butyl hydroperoxide induced oxidative damage in mice erythrocytes: Protection by taurine. Pathophysiology. 2012;19:137-48.

[45] Thornalley P, Trotta R, Stern A. Free radical involvement in the oxidate phenomena induced by tert-butyl hydroperoxide in erythrocytes. Biochimica et Biophysica Acta (BBA)-General Subjects. 1983;759:16-22.

[46] Trotta RJ, Sullivan SG, Stern A. Lipid peroxidation and haemoglobin degradation in red blood cells exposed to tbutyl hydroperoxide. Effects of the hexose monophosphate shunt as mediated by glutathione and ascorbate. Biochemical Journal. 1982;204:405.

[47] Dangles O, Elhabiri M, Brouillard R. Kinetic and thermodynamic investigation of the aluminium-anthocyanin complexation in aqueous solution. Journal of the Chemical Society, Perkin Transactions 2. 1994:2587-96.

[48] Elhabiri M, Figueiredo P, Toki K, Brouillard R. Anthocyanin-aluminium and-gallium complexes in aqueous solution. Journal of the Chemical Society, Perkin Transactions 2. 1997:355-62.

[49] Buchweitz M, Gudi G, Carle R, Kammerer DR, Schulz $\mathrm{H}$. Systematic investigations of anthocyanin-metal interactions by Raman spectroscopy. Journal of Raman Spectroscopy. 2012;43:2001-7.

[50] Landi M. Can anthocyanins be part of the metal homeostasis network in plants. Amer J Agri Biol Sci. 2015;10:170-7.

[51] Pardossi A, Romani M, Carmassi G, Guidi L, Landi M, Incrocci $\mathrm{L}$, et al. Boron accumulation and tolerance in sweet basil (Ocimum basilicum L.) with green or purple leaves. Plant and soil. 2015;395:375-89.

[52] Bratosin D, Mitrofan L, Palii C, Estaquier J, Montreuil J. Novel fluorescence assay using calcein-AM for the determination of human erythrocyte viability and aging. Cytometry Part A. 2005;66:78-84.

[53] Draper H, Hadley M. [43] Malondialdehyde determination as index of lipid Peroxidation. Methods in enzymology. 1990;186:421-31.

[54] Ellman GL. Tissue sulfhydryl groups. Archives of biochemistry and biophysics. 1959;82:70-7.
[55] Brand-Williams W, Cuvelier M-E, Berset C. Use of a free radical method to evaluate antioxidant activity. LWTFood science and Technology. 1995;28:25-30.

[56] Biswas M, Haldar PK, Ghosh AK. Antioxidant and free-radical-scavenging effects of fruits of Dregea volubilis. Journal of natural science, biology, and medicine. 2010;1:29. [57] Alidoost F, Gharagozloo M, Bagherpour B, Jafarian A, Sajjadi SE, Hourfar H, et al. Effects of silymarin on the proliferation and glutathione levels of peripheral blood mononuclear cells from $\beta$-thalassemia major patients. International immunopharmacology. 2006;6:1305-10.

[58] Cighetti G, Duca L, Bortone L, Sala S, Nava I, Fiorelli $\mathrm{G}$, et al. Oxidative status and malondialdehyde in $\beta$-thalassaemia patients. European journal of clinical investigation. 2002;32:55-60.

[59] Kalpravidh RW, Siritanaratkul N, Insain P, Charoensakdi R, Panichkul N, Hatairaktham S, et al. Improvement in oxidative stress and antioxidant parameters in $\beta$-thalassemia/Hb E patients treated with curcuminoids. Clinical biochemistry. 2010;43:424-9.

[60] Koren A, Fink D, Admoni O, Tennenbaum-Rakover Y, Levin C. Non-transferrin bound labile plasma iron and iron overload in Sickle Cell Disease: a comparative study between Sickle Cell Disease and $\beta$ thalassemic patients. European journal of haematology. 2010;84:72-8.

[61] Walter PB, Fung EB, Killilea DW, Jiang Q, Hudes M, Madden $\mathrm{J}$, et al. Oxidative stress and inflammation in iron-overloaded patients with $\beta$-thalassaemia or sickle cell disease. British journal of haematology. 2006;135:254-63.

[62] Trombetta D, Gangemi S, Saija A, Minciullo PL, Cimino F, Cristani M, et al. Increased protein carbonyl groups in the serum of patients affected by thalassemia major. Annals of hematology. 2006;85:520-2.

[63] Waseem F, Khemomal KA, Sajid R. Antioxidant status in beta thalassemia major: a single-center study. Indian Journal of Pathology and Microbiology. 2011;54:761.

[64] Scott MD, Eaton JW. Thalassaemic erythrocytes: cellular suicide arising from iron and glutathione-dependent oxidation reactions? British journal of haematology. 1995;91:811-9.

[65] Rund D, Rachmilewitz E. $\beta$-Thalassemia. New England Journal of Medicine. 2005;353:1135-46.

[66] Scott MD, Van Den Berg J, Repka T, Rouyer-Fessard P, Hebbel RP, Beuzard Y, et al. Effect of excess alphahemoglobin chains on cellular and membrane oxidation in model beta-thalassemic erythrocytes. The Journal of clinical investigation. 1993;91:1706-12.

[67] Almar M, Otero L, Santos C, Gallego JG. Liver glutathione content and glutathione-dependent enzymes of two species of freshwater fish as bioindicators of chemical pollution. Journal of Environmental Science \& Health Part B. 1998;33:769-83.

[68] Albertini M, Chibelli L, Ricciotti R, Fumelli C, Canestrari F, Galli F, et al. Morphological alterations and increased resistance to hemolysis in t-butyl hydroperoxide incubated rbc from elderly subjects. Archives of Gerontology and Geriatrics. 1996;22:423-8.

[69] Rice-Evans C, Baysal E, Pashby DP, Hochstein P. tButyl hydroperoxide-induced perturbations of human erythrocytes as a model for oxidant stress. Biochimica et Biophysica Acta (BBA)-Biomembranes. 1985;815:426-32. 
[70] Senchenkova EY, Skvertchinskaya E, Dobrylko I, Sudnitsyna J, Gambaryan S, Mindukshev I, et al. Experimental oxidative stress-induced death of erythrocytes. The FASEB Journal. 2017;31:1b761-lb.

[71] Lv H, Liu Q, Zhou J, Tan G, Deng X, Ci X. Daphnetinmediated Nrf2 antioxidant signaling pathways ameliorate tert-butyl hydroperoxide (t-BHP)-induced mitochondrial dysfunction and cell death. Free Radical Biology and Medicine. 2017;106:38-52.

[72] Rohn TT, Hinds TR, Vincenzi FF. Inhibition of the $\mathrm{Ca}$ pump of intact red blood cells by t-butyl hydroperoxide: importance of glutathione peroxidase. Biochimica et Biophysica Acta (BBA)-Biomembranes. 1993;1153:67-76.

[73] Chen H-W, Chiang M-T, Wang C-Y, Lii C-K. Inhibition of tert-butyl hydroperoxide-induced cell membrane bleb formation by $\alpha$-tocopherol and glutathione. Food and chemical toxicology. 2000;38:1089-96.

[74] Neto PFT, Gonçalves RP, Elias DBD, Araújo CPd, Magalhães HIF. Analysis of oxidative status and biochemical parameters in adult patients with sickle cell anemia treated with hydroxyurea, Ceará, Brazil. Revista brasileira de hematologia e hemoterapia. 2011;33:207-10.

[75] Comporti M, Signorini C, Buonocore G, Ciccoli L. Iron release, oxidative stress and erythrocyte ageing2 3. Free Radical Biology and Medicine. 2002;32:568-76.

[76] Smeriglio A, Barreca D, Bellocco E, Trombetta D. Chemistry, pharmacology and health benefits of anthocyanins. Phytotherapy Research. 2016;30:1265-86.

[77] Wang H, Cao G, Prior RL. Oxygen radical absorbing capacity of anthocyanins. Journal of agricultural and food chemistry. 1997;45:304-9.

[78] Wang L-S, Stoner GD. Anthocyanins and their role in cancer prevention. Cancer letters. 2008;269:281-90.

[79] Konczak I, Zhang W. Anthocyanins-more than nature's colours. BioMed Research International. 2004;2004:239-40.

[80] Mpiana PT, Lombe BK, Ombeni AM, Tshibangu DS, Wimba LK, Tshilanda DD, et al. In vitro sickling inhibitory effects and anti-sickle erythrocytes hemolysis of Dicliptera colorata CB Clarke, Euphorbia hirta L. and Sorghum bicolor (L.) Moench. 2013.

[81] Sulaiman AA, Hussain SA. Concentration and time dependent cytoprotective effects of anthocyanins against oxidative hemolysis induced by water and lipid soluble free radical initiators: an in vitro study. Oxidants and Antioxidants in Medical Science. 2012;1:133-40.

[82] Narayan M, Naidu KA, Ravishankar G, Srinivas L, Venkataraman L. Antioxidant effect of anthocyanin on enzymatic and non-enzymatic lipid peroxidation. Prostaglandins, Leukotrienes and Essential Fatty Acids (PLEFA). 1999;60:1-4.

[83] Vaya J, Aviram M. Nutritional antioxidants mechanisms of action, analyses of activities and medical applications. Current Medicinal Chemistry-Immunology, Endocrine \& Metabolic Agents. 2001;1:99-117.

[84] Krukoski DW, Comar SR, Claro LM, Leonart MSS, do Nascimento AJ. Effect of vitamin C, deferoxamine, quercetin and rutin against tert-butyl hydroperoxide oxidative damage in human erythrocytes. Hematology. 2009; 14:168-72.
[85] Grinberg LN, Shalev O, Tønnesen HH, Rachmilewitz EA. Studies on curcumin and curcuminoids: XXVI. Antioxidant effects of curcumin on the red blood cell membrane. International journal of pharmaceutics. 1996;132:251-7.

[86] Tsuda T, Shiga K, Ohshima K, Kawakishi S, Osawa T. Inhibition of lipid peroxidation and the active oxygen radical scavenging effect of anthocyanin pigments isolated from Phaseolus vulgaris L. Biochemical Pharmacology. 1996;52:1033-9.

[87] Ollila F, Halling K, Vuorela P, Vuorela H, Slotte JP. Characterization of flavonoid-biomembrane interactions. Archives of biochemistry and biophysics. 2002;399:103-8.

[88] Shinar E, Rachmilewitz E. Oxidative denaturation of red blood cells in thalassemia. Seminars in hematology1990. p. 70-82.

[89] Panat NA, Maurya DK, Ghaskadbi SS, Sandur SK. Troxerutin, a plant flavonoid, protects cells against oxidative stress-induced cell death through radical scavenging mechanism. Food chemistry. 2016;194:32-45.

[90] Li Y, Zhang H, Lu G. The protective effect of procyanidinson tert-butyl hydroperoxide induced human hepatocyte HL7702 cell injury. Animal Cells and Systems. 2015;19:425-31.

[91] Zhu W, Jia Q, Wang Y, Zhang Y, Xia M. The anthocyanin cyanidin-3-O- $\beta$-glucoside, a flavonoid, increases hepatic glutathione synthesis and protects hepatocytes against reactive oxygen species during hyperglycemia: Involvement of a cAMP-PKA-dependent signaling pathway. Free Radical Biology and Medicine. 2012;2:314-27. 